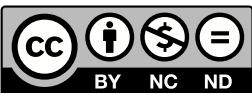

Estudos Teológicos foi licenciado com uma Licença Creative Commons Atribuição - NãoComercial - SemDerivados 3.0 Não Adaptada

http://dx.doi.org/10.22351/etv59i2.3523

\title{
LEGIÃo ROMANA E CRUZ: A DESCONSTRUÇÃo do IMAGINÁRIO POPULAR palestinense por Jesus no Evangelho de Marcos A PARTIR DE CASOS DE EXORCISMOS ${ }^{1}$
}

\author{
Roman legion and cross: the deconstruction of the Palestinian popular imaginary \\ by Jesus in the Gospel of Mark from cases of exorcisms
}

\section{Natalino das Neves ${ }^{2}$ Luiz Alexandre Solano Rossi ${ }^{3}$}

\begin{abstract}
Resumo: O objetivo deste artigo é realizar uma releitura dos atos de exorcismo no Evangelho de Marcos sob a perspectiva dos povos colonizados, dominados por meio das legiões romanas e pela pena de morte na cruz, que formavam o imaginário popular na Palestina no primeiro século. Para atingir esse objetivo será apresentada uma leitura anti-imperialista dos exorcismos de Jesus em Marcos. Em seguida será demonstrado qual foi a gênese do imaginário popular palestinense (legião e cruz) e como os atos de exorcismos no Evangelho de Marcos representam um movimento de resistência ao imaginário popular. Trata-se de uma pesquisa essencialmente bibliográfica, por isso não se pretende fazer análise exegética das perícopes do Evangelho de Marcos. Como resultado se pretende evidenciar que os atos de exorcismos de Jesus, numa leitura anti-imperialista podem ser interpretados como um movimento de resistência popular não violenta à opressão romana.
\end{abstract}

Palavras-chave: Legião Romana. Cruz. Palestina. Evangelho de Marcos. Exorcismo.

\begin{abstract}
The purpose of this article is to perform a rereading of the acts of exorcism in the Gospel of Mark from the perspective of the colonized peoples, dominated by the Roman legions and the death penalty on the cross, which formed the popular imaginary in Palestine in the first century. To achieve this goal, an anti-imperialist reading of the exorcisms of Jesus in Mark will be show. It will then be shown the genesis of the Palestinian popular imagination (legion and cross) and how the acts of exorcism in the Gospel of Mark represent a movement of resistance to the popular imagination. This is essentially a bibliographical research, so it is not intended to make an exegetical analysis of the perícopes of the Gospel of Mark. As a result it is intended to point out
\end{abstract}

\footnotetext{
O artigo foi recebido em 30 de novembro de 2018 e aprovado em 22 de fevereiro de 2019 com base nas avaliações dos pareceristas $a d$ hoc. Pesquisa financiada pela CAPES.

2 Doutor. Pontifícia Universidade Católica do Paraná, Curitiba, PR. E-mail: natalino6612@gmail.com, natalino.neves@ig.com.br

3 Doutor. Pontifícia Universidade Católica do Paraná, Curitiba, PR. E-mail: luiz.rossi@pucpr.br
} 
that the acts of Jesus' exorcisms, in an anti-imperialist reading, can be interpreted as a movement of nonviolent popular resistance to Roman oppression.

Keywords: Roman Legion. Cross. Palestinian. Gospel of Mark. Exorcism.

\section{Introdução}

A interpretação dos evangelhos é influenciada pelo contexto discursivo de seus intérpretes. Os leitores tradicionais, muitas vezes, não percebem os efeitos do imperialismo romano, amparado pelas legiões, no cotidiano dos camponeses na Palestina ${ }^{4}$ do primeiro século. A leitura anti-imperialista ${ }^{5}$ desafia a interpretação padrão e propõe a releitura dos textos evangélicos sob a perspectiva dos povos colonizados que sofriam com a atuação das legiões romanas e a consequente punição pela crucificação, que formavam o imaginário popular na Palestina. Ao falar do "imaginário" do povo da Palestina, recorro ao conceito de imaginário estabelecido por Hilário Franco Júnior ${ }^{6}$ como "um conjunto de imagens visuais e verbais gerado por uma sociedade (ou parcela desta) na sua relação consigo mesma, com outros grupos humanos e com o universo em geral".

Dessa forma, é possível concluir que todo imaginário - deve-se salientar a necessidade de se perceber os muitos imaginários possíveis e não cair no erro de reduzir a "um só imaginário" - é eminentemente coletivo e, portanto, não poderia ser confundido com atividade psíquica individual ou ainda à somatória de imaginações. Mas ainda é preciso salientar que as imaginações também se manifestam em quadros históricos, pois "mesmo ao imaginar, cada indivíduo não deixa de ser membro de uma sociedade e de seus valores objetivos e subjetivos. Porém, por englobar o denominador comum das imaginações, o imaginário as supera, interfere nos mecanismos da realidade palpável (política, econômica, social, cultural) que alimenta a própria imaginação".

O Evangelho de Marcos é o mais breve dos evangelhos, mas "em nada diminui, do ponto de vista qualitativo e global da mensagem, o seu valor literário, a sua força de anúncio e sua intenção teológica"7. Ele é o primeiro do gênero e, consequentemente, o mais próximo do Jesus histórico e escrito em um período de grande

4 A Palestina do século I correspondia à "designação romana para a vasta extensão de terra que abrange os atuais Estados de Israel/Palestina, bem como grande parte da Jordânia, Síria e Líbano” (ASLAN, Reza. Zelota: a vida e a época de Jesus de Nazaré. Rio de Janeiro: Zahar, 2013. p. 22).

5 A leitura contraimperial dos evangelhos assim como a fundamentação teórica sobre o conceito de império pode ser observada na seguinte literatura: ROSSI, Luiz Alexandre S. (Org.). Leitura anti-imperialistas e libertadoras da Bíblia. São Paulo: Terceira Via, 2018. CARTER, W. O evangelho de São Mateus. Comentário sociopolítico e religioso a partir das margens. São Paulo: Paulus, 2003. MIGUES, N. et al. Para além do espírito do império. São Paulo: Paulinas, 2013. CARTER, W. John and Empire: Initial Exploration. New York: T\&T Clark, 2008. CARTER, W. Matthew and Empire: Initial Exploration. Fort Worth: Trinity Press International, 2001.

6 FRANCO, H. Jr. Cocanha - a história de um país imaginário. São Paulo: Companhia das Letras, 1998. p. 23.

7 GRENZER, Mathias; FERNANDES, Leonardo Agostini. Evangelho Segundo Marcos: eleição, partilha e amor. São Paulo: Paulinas, 2012. p. 7. 
enfrentamento ao Império Romano pela comunidade judaica. Desse modo, torna-se um excelente conteúdo para identificar como a literatura evangélica é utilizada para demonstrar, além da experiência religiosa, o conflito que estava presente na pregação do evangelho e nos atos de Jesus, em especial, nas práticas de exorcismo.

\section{Os exorcismos de Jesus em Marcos em chave de leitura contraimperial}

Os evangelhos apresentam Jesus como camponês judeu que atraiu multidões por meio de discursos elaborados, curas, milagres e sinais que realizava. O Evangelho de Marcos, especificamente, inicia o primeiro ato milagroso com um exorcismo de Jesus que faz sua fama se espalhar por toda região (Mc 1.21-28). Atos semelhantes se repetem por mais duas vezes, a saber, a) expulsão da "Legião" de demônios no seu desembarque em Gerasa, na Decápole (Mc 5.1-20); b) a expulsão do espírito impuro da filha de uma mulher, quando chega em Tiro (Mc 7.24-30) ${ }^{8}$.

Brown, ao analisar o Evangelho de Marcos, afirma que a compreensão sobre Jesus e a vocação de seus seguidores somente é possível se o estudo estiver "intimamente ligado ao quadro de sua vitória por meio do sofrimento". Defende que as narrativas de exorcismo são partes indissociáveis do ensinamento que acompanha a proclamação do reino e indica que "a presença do mal, visível na aflição humana, no sofrimento e no pecado precisa ser contraposta; o demônio, por sua vez, deve ser derrotado" ${ }^{10}$. Ressalta ainda que as pessoas do primeiro século tinham uma mentalidade "bem diferente da nossa" maneira como viam a relação entre religião e política; saúde e doença. Ele assevera que os distúrbios e tensões a que os palestinos estavam submetidos era algo "comum em governo estrangeiro" e que, apesar da atuação de dois prefeitos estrangeiros atuando por 20 anos seguidos, aquele não foi "um tempo de revolução violenta". Assim, as multidões se aglomeravam em torno de Jesus e seu movimento em busca de curas, expulsão de demônios e outros males como algo independente das mudanças sociais, econômicas, políticas e culturais estabelecidas pelo Império Romano, ou seja, esses males precediam a chegada dos romanos. ${ }^{12}$ Nessa visão padrão, Jesus é apresentado como condescendente com o Império Romano e reduzido a uma mera figura religiosa, sem relevância ou implicações contrárias ao status quo romano.

A influência preponderante do pensamento de Brown perdurou até a década de 1970. Após essa data, alguns pesquisadores demonstram um interesse mais acurado sobre o contexto social dos evangelhos. Entre eles, Malina investiga a solução que

8 SCHIAVO, Luigi. 2000 Demônios na Decápole: exegese, história, conflitos e interpretações de Mc 5,120. 1999. Dissertação (Mestrado em Ciências da Religião) - Universidade Metodista de São Paulo, São Bernardo do Campo, 1999. p. 206.

9 BROWN, Raymond Edward. Introdução ao Novo Testamento. São Paulo: Paulinas, 2004. p. 205.

${ }^{10}$ BROWN, 2004, p. 205.

${ }^{11}$ BROWN, 2004, p. 213.

12 BROWN, 2004, p. 125. 
Jesus pretendia apresentar ao proclamar a chegada do reino de Deus. Ele chega a conclusão de que a resposta era "política, não metafórica e muito menos, "espiritual"'13. Acrescenta que a Bíblia será "necessariamente mal compreendida se algum leitor dela não está fundamentado numa apreciação dos sistemas sociais nos quais seus documentos surgiram" 14 . No caso específico das narrativas de exorcismos, defende a abordagem sociológica da época e na forma como as sociedades se relacionavam com religião e política, saúde e doença. Crossan ${ }^{15}$, por sua vez, defende que remover o que é radicalmente subversivo, socialmente revolucionário e politicamente perigoso das ações de Jesus é deixar sua vida sem significado e sua morte inexplicável.

Outro pesquisador que vem contribuindo de forma significativa para uma nova abordagem dos evangelhos com uma série de livros é Horsley. Ele vem combatendo a despolitização de Jesus, da Judeia, da Galileia e do Império Romano. ${ }^{16}$ Para ele, não há como compreender as palavras e as ações de Jesus desconsiderando "como o imperialismo romano determinava as condições de vida na Galileia e em Jerusalém"17. Horsley defende uma nova forma de compreender o poder, a política e a religião do Império Romano, pois "não havia separação entre política e religião"18. Ele defende que a condição colonial a que estavam submetidos os palestinos, como povo colonizado, era propícia à formação de movimentos revolucionários em busca de renovação do modo de vida habitual. ${ }^{19} \mathrm{O}$ biblista sugere que seja observado o contexto dos evangelhos, em que a violência na região era "institucionalizada" para atender os interesses dos romanos. A conquista imperial era marcada pelo uso abusivo da violência e regida por uma ideologia autolegitimadora que defendia os amigos e aliados e tinha como objetivo instaurar em todo território do império a "civilização" e "paz", uma nova ordem imperial. ${ }^{20}$ Ele afirma que "a violência estrutural foi construída e inserida na própria estrutura da sociedade e manifesta-se como um poder desigual e, consequentemente, como chances desiguais na vida"21.

Dessa forma, Horsley questiona a legitimidade da força utilizada pelos romanos: "violência seria então o uso ilegítimo ou não autorizado de poder contra a vontade ou desejo de outros. Dessa maneira, um governo legítimo usaria força para reter e eliminar o abuso e dano criminal em relação a seus cidadãos"22. Para ele, o Evangelho de Marcos retrata uma luta envolvendo o projeto de renovação de Israel por Jesus no

13 MALINA, Bruce J. O Evangelho Social de Jesus: o Reino de Deus em Perspectiva Mediterrânea. São Paulo: Paulus, 2004. p. 11.

14 MALINA, 2004, p. 15.

${ }^{15}$ CROSSAN, John Dominic. O essencial de Jesus: frases originais e primeiras imagens. Belo Horizonte: Jardim dos Livros, 2008. p. 15.

16 HORSLEY, Richard A. Jesus e o império: o Reino de Deus e a nova desordem mundial. São Paulo: Paulus, 2004a. p. 11-18.

17 HORSLEY, 2004a, p. 19.

${ }^{18}$ HORSLEY, Richard A. Paulo e o império: religião e poder na sociedade imperial. São Paulo: Paulus, 2004b. p. 21.

19 HORSLEY, Richard A. Jesus e a Espiral da Violência. São Paulo: Paulus, 2010. p. 13

${ }^{20}$ HORSLEY, 2010, p. 29.

${ }^{21}$ HORSLEY, 2010, p. 21.

${ }^{22}$ HORSLEY, 2010, p. 20. 
sentido contrário aos interesses de Roma e aos líderes judaicos colaboracionistas. Os exorcismos narrados nesse evangelho se constituiriam em componentes proeminentes do programa de Jesus ${ }^{23}$ e deveriam ser entendidos como batalhas na luta contra o imperialismo romano e o colonialismo. Horsley cita como exemplo a perícope de Marcos 5.1-20 como exemplo dos "efeitos da violência imperial romana, um deslocado protesto contra esses efeitos e uma atitude de autoproteção contra um ataque suicida em relação aos romanos". Comenta que o ato de Jesus é visto pelos proprietários de porcos, que pedem para que ele se retire da região, como ameaça ao seu relacionamento de equilíbrio à ordem romana. ${ }^{24}$ Myers $^{25}$ reforça que as duas narrativas de exorcismos posteriores: Marcos 7.24ss (libertação da filha da mulher siro-fenícia) e Marcos 9.14ss (libertação do rapaz mudo), também estão ligadas às estruturas de poder e de alienação no mundo social. A primeira narrativa denota o profundo abismo existente entre judeus e gentios; na segunda, o esforço exaustivo para acreditar na nova ordem do Reino.

As narrativas de Marcos que deram origem ao gênero literário "evangelho" e serviram de base para os demais evangelhos se tornaram fundamentais para entender a repercussão, principalmente dos atos de exorcismos de Jesus que fornecem mais informações do que um simples relato de atividades de taumaturgo, comum à época. Eles representam o impacto econômico, social, ideológico e cultural produzido pelo poder imperialista romano na vida dos judeus palestinenses do primeiro século. Um impacto social a partir de atos de cura e de exorcismo de Jesus muito bem descrito por Richter Reimer ${ }^{26}$ :

[...] podem ser interpretadas no plano da significância, que permite uma interpretação na qual interagem dois momentos distintos e interligados da narrativa: a pessoa doente/ possessa incorpora e representa a coesão social através de exclusão, a qual indica para a experiência pessoal e social de caos e desequilíbrio; a prática libertadora de Jesus indica para a ruptura com esse esquema através do perdão, da cura, do exorcismo. Assim, conclui-se que a ação de Jesus intervém nas relações sociais e simbólicas de corpos doentes e sofridos, reconstruindo, portanto, também identidades pessoais e sociais.

\section{As legiões romanas e a nova ordem imperial}

O início da dominação do Império Romano sobre a região da Palestina ocorre em 63 a.C. com a conquista do território pelo general Pompeu, sem muitas dificuldades. Ele reintegra Hircano como sumo sacerdote e impõe-lhe um novo controle, obrigando-o a prestar contas de suas funções administrativas. A partir de então, a Palestina

${ }^{23}$ HORSLEY, Richard A. Hearing the whole story: the politics of plot in Mark's Gospel. Louisville: Westminster John Knox, 2001. p. 121.

${ }^{24}$ HORSLEY, 2001, p. 145.

${ }^{25}$ MYERS, Ched. O Evangelho de Marcos. Trad. I. F. L. Ferreira. São Paulo: Paulinas, 1992. p. 183-184.

${ }^{26}$ RICHTER REIMER, Ivoni. Milagre das mãos: curas e exorcismos de Jesus em seu contexto histórico-cultural. São Leopoldo: Oikos; Goiânia: UCG, 2008. p. 66. 
passa por uma agressiva transformação de caráter social, político e econômico que mudaria significativamente a vida de seus habitantes e seus descendentes por séculos.

A Palestina - cuja economia era baseada na agricultura - já havia tido experiências de opressão imperialistas antes dos romanos por meio de extorsão de excedentes agrícolas e escravização. No entanto, a comercialização romana era bem mais invasiva. A unidade política do império era mantida pelo controle militar por meio de legiões de soldados estabelecidas em centros urbanos espalhados pelas províncias romanas. Os romanos se apropriavam não somente dos excedentes agrícolas dos camponeses, como também de suas terras, geralmente devido a dívidas contraídas e pela impossibilidade de pagamento de tributos excessivos. Elliott ${ }^{27}$ assevera que no imperialismo "a dignidade das vítimas como seres humanos não é reconhecida, exceto quando esse reconhecimento redunda em gloriosa benevolência dos soberanos". O exército romano, em seu avanço sobre os territórios palestinos, tratou os habitantes com brutalidade excessiva com o intuito de induzir o povo à submissão. Para os camponeses, a dominação romana não significava somente a submissão à uma pesada tributação, mas, acima de tudo, uma grave ameaça à própria existência por meio da expulsão de suas próprias terras. ${ }^{28} \mathrm{~A}$ instabilidade e penúria a que foi submetida fez da Palestina um dos maiores focos de resistência contra a expansão imperial romana.

Para os romanos, toda a situação de injustiça sistêmica e opressão institucionalizada era "legitimada" por uma teologia imperial que afirmava ser esse império universal, desejado e protegido pelos deuses. Uma dominação sustentada por um exército forte e bem estruturado e sob o pretexto de uma paz garantida, a Pax Romana ${ }^{29}$. Os romanos faziam operações militares periódicas em pontos estratégicos da Galileia para garantir a cobrança excessiva de tributos e arrecadação de taxas especiais. Todo aparato tinha por objetivo manter a estrutura de poder e proporcionar benefícios para uma minoria que formava o grupo social dominante: representantes oficiais dos romanos e a elite do grupo religioso judaico que também estava a serviço dos romanos. Essa situação exigia dos camponeses um grande esforço, que na maioria das vezes não era suficiente para evitar a miséria e desumanização. Elliott ${ }^{30}$ afirma que, em um mundo controlado pela ideologia imperialista, "o sofrimento coletivo de milhares e milhares de seres humanos não chega a ser o impedimento para a política”. A política de dominação romana aumentava cada vez mais o número de pobres, marginalizados, desempregados, enfermos e agricultores sem terra.

Elliott ${ }^{31}$ afirma que "impérios subsistem pelo domínio de outros povos", debaixo de prerrogativas de poder unilaterais, de cima para baixo, para definir a vida ou

27 ELLIOTT, Neil. A mensagem anti-imperial da cruz. In: HORSLEY, 2004b, p. 182.

${ }^{28}$ HORSLEY, Richard A.; HANSON, John S. Bandidos, Profetas e Messias: Movimentos Populares no Tempo de Jesus. Trad. Edwino A. Royer. São Paulo: Paulus, 1995. p. 43-44.

29 BRUNT, P. A. Laus imperii. In: HORSLEY, 2004b, p. 33-35.

${ }^{30}$ ELLIOTT, Neil. A arrogância das nações: A Carta aos Romanos à sombra do Império. São Paulo: Paulus, 2010. p. 182.

31 ELLIOTT, 2010, p. 181. 
morte das pessoas com base na clemência imperial. ${ }^{32}$ Para isso, eles precisavam de um meio eficiente de dominação e manutenção do controle sobre os povos conquistados. A superioridade e dominação romana eram sustentadas pela capacidade militar, inclusive a conquista do cargo de imperador era influenciada pelo número de legiões que o pretendente tinha à sua disposição. $\mathrm{O}$ número de soldados por legião não é unanimidade entre os autores. ${ }^{33}$ Os legionários, em condições normais, eram recrutados dentre os cidadãos romanos, porém em situações de redução do quadro sem possibilidade de reposição por cidadãos romanos, essa regra era desprezada e se recrutava também quem não era cidadão romano.

A força militar do império era garantida pela disposição da maioria das legiões em províncias fronteiriças. Segundo Koester ${ }^{34}$, a legião era comandada por um legado de classe senatorial, auxiliado por seis tribunos militares. ${ }^{35}$ Não se pode desconsiderar a guarda imperial ${ }^{36}$, uma subdivisão especial do exército conhecida como "os pretorianos". Quando o exército romano, formado pelas suas legiões, estava em marcha, o barulho e a sensação de medo que causava nos seus oponentes eram assustadores e traziam resultados devastadores.

\section{A cruz como instrumento de tortura}

Jesus foi vítima da morte mais violenta sob o regime da Pax Romana, a crucificação, justamente quando passa a atuar na região da procuradoria romana composta pela Judeia, Samaria e a Idumeia. Essa região se destacava das demais devido a toda importância que envolvia o grande centro urbano de Jerusalém. A morte de cruz, símbolo do maior controle romano sob as ações consideradas subversivas e perigosas ao império, era executada por integrantes da legião romana. Portanto o relato da execução de Jesus reflete dois elementos que faziam parte do imaginário popular dos habitantes da Palestina do primeiro século, a legião romana e a cruz. Esse imaginário judaico foi o elemento motivador dos numerosos levantes populares.

Crossan assegura que os romanos não crucificavam pessoas simplesmente por palavras ou ideias, mas somente os considerados subversivos. Para ele, "se Jesus tivesse sido apenas uma questão de palavras ou ideias, os romanos provavelmente o

32 A ideologia imperial romana determinava que a misericórdia fosse uma prerrogativa dos poderosos, “apropriada somente quando o destinatário da misericórdia é realmente impotente e submisso" (ELLIOTT, 2010, p. 180).

33 Esse número podia variar dependendo da província e da época, porém a maioria dos pesquisadores varia entre cinco e seis mil soldados. O mais usual é considerar a quantidade de seis mil soldados. SOUTHERN, P. The Roman Army. Oxford: Oxford University Press, 2007. p. 99; CROSSAN, John Dominic. Jesus: uma biografia revolucionária. Rio de Janeiro: Imago, 1995. p. 147.

34 KOESTER, Helmut. Introdução ao Novo Testamento. São Paulo: Paulus, 2005. v. 1, p. 237.

35 O primeiro dos tribunos procedia do senado e os demais da classe dos equestres, potenciais comandantes das tropas auxiliares. Enquanto os centuriões eram oficiais permanentes do exército, os tribunos serviam por períodos limitados.

${ }^{36}$ A guarda imperial era a única unidade bélica permanente em solo italiano, portanto fora do solo judeu. Ela era estruturada com 4.500 soldados e comandados por dois prefeitos. 
teriam ignorado e, talvez, não estaríamos falando dele hoje. O movimento do seu Reino, entretanto, com suas curas e exorcismos, era ação e prática, não pensamento e teoria" ${ }^{37}$. Ele vê o movimento de Jesus como uma fonte de empoderamento ao campesinato, que era duramente explorado e oprimido pelo Império Romano que buscava a legitimação de suas práticas sob a pretensa Pax Romana oferecida como um "benefício" aos povos subjugados. Segundo Crossan ${ }^{38}$, os camponeses judeus já tinham uma tendência a não aceitação passiva dos altos impostos, da agricultura de subsistência, do empobrecimento pelas dívidas e expropriação de suas terras, "oferecendo resistência declarada ou velada acima do que se podia esperar de qualquer campesinato colonial". Eles teriam uma motivação a mais, se liderados por uma figura messiânica e popular.

Horsley $^{39}$ corrobora as afirmações anteriores ao afirmar que o "cristianismo começou como um movimento anti-imperial". E as legiões romanas que exerciam a violência excessiva foram instrumentos para estabelecer as condições econômicas, sociais, políticas e culturais que deram origem ao cristianismo original. Por isso estava no imaginário do povo da Palestina, juntamente com a cruz, outro símbolo da opressão. Para os membros do seguimento de Jesus esse imaginário era mais forte ainda, pois seu grande líder, tido como um subversivo também é condenado a morrer nela. A crucificação era um dos maiores trunfos dos romanos, pois por meio dela eles aterrorizavam os povos subjugados. Segundo $\mathrm{Hengel}^{40}$, a crucificação era a punição típica para escravos como instrumento de dissuasão e terror para os povos resistentes ao domínio romano. Horsley e Hanson ${ }^{41}$ afirmam que "repetidamente, os exércitos romanos incendiaram e destruíram completamente cidades e massacraram, crucificaram ou escravizaram suas populações". A morte de cruz era desprezada tanto por judeus como pelos romanos. Os judeus por questões religiosas e os romanos por questões políticas. Wengst ${ }^{42}$ afirma que o fato de Pôncio Pilatos ter mandado executar Jesus na cruz "mostra que a morte de Jesus está indissoluvelmente ligada à paz política que reinava naquele tempo, a Pax Romana, estabelecida e garantida pelo poder romano".

Para os judeus, a morte de cruz era uma maldição (Dt 21.23). Na cultura judaica não se esperava um Messias que sofresse e morresse. "Alguém que fora condenado à morte pelo supremo tribunal judaico e injuriosamente executado não poderia ser $\mathrm{o}$ salvador esperado." ${ }^{\prime 3}$ Paulo afirma, quando escreve aos gálatas (3.13), que Cristo nos resgatou da maldição da Lei, fazendo-se maldição por nós morrendo na cruz, e faz uma referência à Deuteronômio 21,23: "[...] maldito todo aquele que for pendurado no madeiro". Por essa afirmação, Paulo foi criticado por estudiosos do Antigo Testamento por oferecer uma interpretação apenas espirituosa, porque Deuteronômio 21.23

${ }^{37}$ CROSSAN, 2008, p. 15.

${ }^{38}$ CROSSAN, 2008, p. 17.

${ }^{39}$ HORSLEY, 2004b, p. 9.

${ }^{40}$ HENGEL, M. Crucifixion: in the ancient world and the folly of the message of the cross. Fortress: Philadelphia, 1978. p. 51.

${ }^{41}$ HORSLEY; HANSON, 1985, p. 44.

${ }^{42}$ WENGST, C. Pax Romana: pretensão e realidade. Trad. Antônio M. da Torre. São Paulo: Paulinas, 1991. p. 10.

${ }^{43}$ BARTH, Gerhard. Ele morreu por nós: a compreensão da morte de Jesus Cristo no Novo Testamento. São Leopoldo: Sinodal, 1997. p. 19. 
originalmente não trataria de morte por crucificação. No entanto, Barth ${ }^{44}$ alega que isso mudou com a descoberta do Rolo do Templo do mar Morto: "Em 11QT Temple 64.7-13, a maldição de Deuteronômio 21.23 é vinculada claramente também com a pena capital da crucificação". A interpretação da morte de cruz que era complicada para um judeu foi absorvida e ressignificada pelo movimento de Jesus. ${ }^{45} \mathrm{O}$ apóstolo Paulo, quando escreveu aos coríntios, afirma que o cristo crucificado é uma "pedra de tropeço" para os judeus e loucura para os gentios (1Co 1.18-23).

Elliot ${ }^{46}$ afirma que, como meio de punição capital de crimes hediondos, a crucificação era a "pena romana suprema", no entanto, na sua grande maioria, destinada às classes inferiores. Os romanos reservavam a morte de cruz para seus inimigos políticos. Pessoas que eram consideradas um perigo para a manutenção do imperialismo romano, ou seja, pessoas consideradas por eles como rebeldes e subversivos que se recusavam a obedecer cegamente às ordens impostas pelos poderosos romanos. Essa morte era considerada tão terrível que, pela lei romana, um cidadão romano não poderia ser executado dessa forma.

Quando Jesus foi encaminhado para a morte de cruz, ao seu lado estavam dois ladrões, como geralmente são apresentados. O termo grego utilizado é lestai, muitas vezes traduzido como "ladrões", mas que significa "bandidos" e era a designação romana mais comum para um insurreto ou rebelde. ${ }^{47} \mathrm{O}$ "crime" de Jesus, na concepção da ideologia romana, foi o de buscar o poder político de um rei, o mesmo crime pelo qual foram mortos quase todos os outros que se apresentaram como messias da época. Storniolo ${ }^{48}$ afirma que não eram simples ladrões, os romanos os consideravam bandidos e "subversivos que almejavam o poder para derrubar o poder romano". Na concepção romana, Jesus é colocado em mesma condição de condenação. A crucificação de Jesus incomodou também os próprios seguidores. Schiavo ${ }^{49}$ afirma que a memória e a imagem de Jesus crucificado "Incomodavam os judeus, para quem o Messias seria um vencedor, não um perdedor. Incomodavam os cristãos, cuja referência era um deus rejeitado e morto num patíbulo". A morte "vergonhosa" de Jesus na cruz como um revolucionário e subversivo não atendia as expectativas geradas pelo seu seguimento. As atitudes e o ensino de Jesus realmente acabam por defini-lo como um revolucionário que confronta o sistema de dominação romano.

Assim, o autor de Marcos, décadas depois da crucificação de Jesus, faz questão de destacar a autoridade dele e o controle sobre todos os poderes vigentes por meio das narrativas de exorcismo, em que as legiões se submetem a ele. Klaus Berger ${ }^{50}$ defende a ideia de que a narrativa de milagre na literatura cristã primitiva é uma "tentati-

\footnotetext{
44 BARTH, 1997, p. 19.

${ }^{45}$ ROSSI, Luiz Alexandre S. Messianismo e Modernidade. Repensando o messianismo a partir das vítimas. São Paulo: Paulus, 2008.

${ }^{46}$ ELLIOTT, 2004, p. 169.

47 STORNIOLO, Ivo. Como ler o Evangelho de Mateus: o caminho da justiça. São Paulo: Paulus, 1991. p. 199.

48 STORNIOLO, 1991, p. 199.

49 SCHIAVO, Luigi. Anjos e Messias: messianismos judaicos e origem da cristologia. São Paulo: Paulinas, 2006. p. 140.

${ }^{50}$ BERGER, Klaus. Hermenêutica do Novo Testamento. São Leopoldo: IEPG; Sinodal, 1999. p. 341.
} 
va de reconstrução de uma experiência, não da explicação dos próprios milagres nem ainda da aplicação". Considera-se que "não se está pensando em facticidade pura, e sim na demonstração do poder de Deus 'diante' de pessoas (porque se trata de missão ou apologética)". Em termos da proclamação do reino de Deus, Ekkehard W. Stegemann e Wolfgang Stegemann ${ }^{51}$ afirmam que os "poderes milagrosos são interpretados como eventos escatológicos, ou seja, como o despontar da vitória sobre o reino dos demônios e dos espíritos imundos".

\section{A desconstrução do imaginário popular palestinense nos exorcismos de Marcos}

As narrativas de exorcismos dos sinóticos têm por base o Evangelho de Marcos, complementado por conteúdo de suas próprias fontes. ${ }^{52}$ Segundo Rabuske ${ }^{53}$, Marcos apresenta maior número de material narrativo sobre atos de exorcismo, com paralelos nos sinóticos; além do conteúdo dos “ditos do Senhor", em que o tema do exorcismo é abordado por meio da controvérsia em torno de Belzebu (Mc 3.20-30). Os evangelhos sinóticos, especialmente a tradição de Marcos, contêm uma grande quantidade de narrativas de atividades exorcistas de Jesus, libertando pessoas de possessões de espíritos considerados imundos e reconhecidos como agentes demoníacos. Quando a possessão demoníaca ocorre em massa, ela é identificada como legião de demônios incorporada à pessoa referenciada como possessa (Mc 5.1ss). A relação da legião romana com anjos demoníacos está implícita na atuação de Jesus, que tem uma relação clara para com a realidade social e política de sua época, comandada pelo Império Romano. Wengst ${ }^{54}$ assevera que em uma sociedade que expressa seus problemas em linguagem mítica, a ocorrência de possessão em massa poderia ser condicionada pela condição social. "É o que se pode mostrar nas histórias de possessos nos evangelhos". Soares e Correia Júnior ${ }^{55}$ corroboram essa indicação ao afirmar que "a presença satânica é como a devastadora ocupação das tropas romanas". O anúncio da chegada do reino de Deus manifesto por meio de curas e exorcismos, expressões da ação demoníaca sobre as pessoas, representa a libertação da imposição opressora e dominadora das forças do mal, que no caso é representada pela ação do Império Romano. A fala dos demônios que se manifestam nos exorcismos demonstra o reconhecimento da chegada do Reino.

51 STEGEMANN, Ekkehard W.; STEGEMANN, Wolfgang. História social do protocristianismo: os primórdios no judaísmo e as comunidades de Cristo no mundo mediterrâneo. São Paulo: Paulus; São Leopoldo: Sinodal, 2004. p. 235.

52 MEIER, 1998, p. 170.

${ }^{53}$ RABUSKE, Irineu J. Jesus exorcista: estudo exegético e hermenêutico de Mc 3,20-30. São Paulo: Paulinas, 2001. p. 37-39.

54 WENGST, 1991, p. 97.

55 SOARES, 2002, p. 222. 
Rüsen ${ }^{56}$ afirma que os relatos históricos do passado são compreensíveis "quando se interpretam os fatos à luz dos significados que lhes foram atribuídos na forma de objeções culturais das intenções humanas". Grenzer e Fernandes ${ }^{57}$ afirmam que o autor e os destinatários do evangelho marcano não são pessoas neutras às narrativas, "pois a linguagem utilizada é envolvente e impactante. Contudo, não é facilmente percebida e estabelecida pelo ouvinte-leitor contemporâneo". Esse evangelho desperta interesse pela concisão precisa das narrações, relidas sob perspectivas religiosas e motivações políticas, nas entrelinhas muitas vezes subversivas. Segundo Soares e Correia Júnior ${ }^{58}$, o surgimento do Evangelho de Marcos está relacionado a três fatos importantes:

[...] a) O desaparecimento da primeira geração de discípulos e discípulas de Jesus, testemunhas das ações e palavras de Jesus (testemunhas apostólicas); b) As comunidades já acolhem gentios, pessoas que não conhecem a cultura judaica, e isso é motivo de crise e conflito; c) O judaísmo está em guerra contra Roma: o texto, sem dúvida, está em relação com a guerra, quer tenha sido escrito imediatamente antes da guerra, quer durante a guerra ou logo depois.

A análise comparativa entre o momento histórico da narrativa do evangelho (narrativa realista) e o momento histórico em que vivia a comunidade marcana possibilitará a aproximação com a intenção do autor do evangelho ao incluir a narrativa no evangelho e da construção de sentido pretendido (ação simbólica/ideológica). No plano simbólico-ideológico, a libertação ocorrida com a atuação exorcista de Jesus representa a vitória sobre as forças do mal (representantes do Império Romano). As forças do mal estão representadas não somente pelas legiões, mas também por outros símbolos como as estruturas sociais, econômicas, religiosas, políticas e ideológicas do Império Romano. Bietenhard ${ }^{59}$ afirma que Jesus, com autoridade de Deus, demonstrou a superioridade de sua força diante dos demônios e espíritos impuros, que tiveram que se render e curvar diante dele.

Mais especificamente, o texto de Marcos 5.1-17, que retrata um episódio muito particular da ação de Jesus ao libertar o possesso de Gadara/Gerasa, suscita várias perguntas e algumas delas se fazem especiais: a) $\mathrm{O}$ episódio revela alguma relação entre a opressão que o Império Romano exercia sobre a Palestina e o fenômeno de tantas pessoas possuídas pelo demônio à época de Jesus $?^{60}$ b) Seria alguma forma

${ }^{56}$ RÜSEN, Jörn. História Viva: teoria da história: formas e funções do conhecimento histórico. Brasília: UnB, 2007. p. 137.

57 GRENZER; FERNANDES, 2012, p. 77.

58 SOARES; CORREIA JÚNIOR, 2002, p. 13.

59 BIETENHARD, H. “Ekballlo”. In: COENEN, Lothar; BROWN, Colin (Orgs.). Dicionário Internacional de Teologia do Novo Testamento. 2. ed. Trad. Gordon Chown. São Paulo: Vida Nova, 2000. v. 1, p. 518.

${ }^{60}$ Pagola afirma que o fenômeno da possessão demoníaca era praticamente ausente em séculos anteriores a Jesus. Sua afirmação ganha relevo ao percebermos que a possessão se tornou um elemento muito difuso no tempo de Jesus. Ainda segundo ele, seriam cada vez mais numerosos os investigadores que enfatizam a dimensão política que os exorcismos de Jesus poderiam ter. Entre eles são citados: Hollenbach, Horsley, Crossan, Sanders, Evans, Herzog II, Guijarro (PAGOLA, Jose A. Jesus, aproximação histórica. Petrópolis: Vozes, 2010. p. 413). 
de se rebelar contra a submissão imposta pelo domínio romano? Mesmo que não entendamos a cura do endemoninhado geraseno como estritamente histórica, talvez seja possível afirmar que o imaginário do povo da Palestina estivesse povoado pelas imagens da opressão de Roma. Sim, provavelmente estamos diante da cura de um indivíduo, mas também não podemos e não devemos ignorar o simbolismo que a narrativa traz em seu interior. Muito possivelmente o caráter simbólico do texto incorpora e gera mais sentido. Consequentemente, é possível afirmar que diante dos episódios de exorcismos de Jesus e, principalmente ao do geraseno, as pessoas simples da Galileia entrevissem a rápida derrota dos romanos ou, nas palavras de Crossan ${ }^{61}$ quando afirma que "o relato é um resumo do sonho de todo revolucionário judeu" e de Soares e Correia Júnior ${ }^{62}$ indicando que "a presença satânica é como a devastadora ocupação das tropas romanas".

De acordo com o relato, o demônio é um só, mas se chama de "legião", porque são muitos. Trata-se do mesmo termo para se referir à divisão armada de Roma que controlava com mão de ferro a Palestina.$^{63}$ Deve-se ressaltar que "conhecer o nome" de alguém, naquela cultura, significava a pretensão de dominar essa pessoa e ser mais forte do que ela.$^{64} \mathrm{O}$ espírito impuro, portanto, ao responder a Jesus, procura demonstrar todo seu poder e, com isso, a partir do simbólico, subjugar o mais fraco. Os demônios expulsos por Jesus entram nos porcos, que eram considerados "os animais mais impuros de todos e os que melhor podiam definir os romanos" ${ }^{16}$. Chouraqui ${ }^{66}$ é ainda mais incisivo ao afirmar que "o homem está possuído pelo demônio como Israel pelas legiões romanas". Bortolini ${ }^{67}$ segue na mesma direção ao expressar que o "possesso é símbolo de um povo politicamente dominado". O texto é narrado à procura de seu clímax e, por conta disso, os porcos se precipitam ao mar, onde a "resistência judaica queria vê-los submersos para sempre" ${ }^{\prime 6}$. Dessa forma, a ruína dos porcos também significaria a libertação da escravidão sob o poder romano. Storniolo ${ }^{69}$ ratifica a informação: "também o porco era considerado animal sagrado e um dos símbolos do poder romano". O porco era precisamente o símbolo da X Legião Romana que controlava, a partir da Síria, a região palestina. Ao escutar o discurso de Jesus, os ouvintes não podiam pensar senão na legião romana estabelecida em Damasco e encarregada de manter a ordem naquela região e de fazer respeitar a Pax Romana. Roma havia enviado à

${ }^{61}$ CROSSAN, John Dominique. O Jesus histórico: a vida de um camponês judeu do Mediterrâneo. Trad. André Cardoso. Rio de Janeiro: Imago, 1994. p. 352.

${ }^{62}$ SOARES, Sebastião Armando Gamaleira; CORREIA JÚNIOR, João Luiz. Evangelho de Marcos: Vol 1:1-8, Refazer a casa. Petrópolis: Vozes, 2002. p. 222

${ }^{63}$ MEIER, John Paul. Um judeu marginal: repensando o Jesus histórico. Trad. Laura Rumchinsky. Rio de Janeiro: Imago, 1998. v. II, Livro 3.

${ }^{64}$ ROSSI, Luiz Alexandre Solano. "Meu nome é Legião" - Uma leitura de Marcos 5,1-17 a partir da ação letal da legião romana. Revista Reflexus, v. 5, n. 6, 2011. p. 179.

${ }^{65}$ PAGOLA, 2010, p. 208.

${ }^{66}$ CHOURAQUI, A. Marcos. Rio de Janeiro: Imago, 1996. p. 93.

${ }^{67}$ BORTOLINI, J. O Evangelho de Marcos. São Paulo: Paulus, 2003. p. 105.

${ }^{68}$ PAGOLA, 2010, p. 208.

${ }^{69}$ STORNIOLO, Ivo. Como ler o evangelho de Lucas. São Paulo: Paulus, 1992. p. 89. 
Judeia e à Síria suas melhores tropas para manter a ordem constantemente perturbada pela população revoltosa. ${ }^{70}$

Reiterando as informações acima, Aslan $^{71}$ destaca que os evangelhos foram escritos na perspectiva da fé e tradição que foi se formando nas primeiras décadas e à medida que o Jesus histórico se distanciava no passado. Para ele, é possível enquadrar o Jesus histórico como um zelota, um líder revolucionário judeu, que acaba sendo executado pelas autoridades romanas como ocorreu com outros que se apresentaram como o messias. Aslan dá uma atenção especial ao Evangelho de Marcos e a fonte Q para sustentar suas afirmações. Ele, em partes, vai ao encontro do Jesus revolucionário apresentado por John Dominic Crossan ${ }^{72}$. Ao encontro das considerações de Malina e Horsley, John D. Crossan ao comentar sobre Mc 5.1-20 corrobora a afirmação de que não há como ignorar o simbolismo embutido na narrativa do endemoninhado geraseno. O demônio que possuía o geraseno, chamado Legião, um símbolo do poder romano, é lançado ao mar. Esse era o sonho de todo revolucionário judeu. Portanto um relato genuinamente anti-imperial. ${ }^{73}$

Segundo Hoornaert ${ }^{74}$, parte do seguimento de Jesus teve influência do imaginário apocalíptico, que já era "comum aos discípulos da primeira geração". Esse imaginário era influenciado principalmente pelo livro apocalíptico de Daniel, que faz uma interpretação da história do povo judeu por meio de metáforas como forma de revelar (apocalipse) o universo como um campo de batalha entre Deus e seus anjos contra Satanás e seus anjos. Assim, ele explica a vitória dos macabeus (anjos de Deus) sobre os sírios (Antíoco IV e seu exército como anjos demoníacos) como uma vitória de Deus e seus anjos de luz contra Satanás e seu exército demoníaco. Schiavo ${ }^{75}$ afirma que "é no contexto do mito do combate que deve ser lida e interpretada a estrutura simbólica da batalha escatológica, própria do judaísmo pós-exílico”. O dualismo, herdado principalmente dos persas, se impõe como chave de interpretação da história, com base na batalha entre as forças celestes do bem e do mal (oposição cósmica), enquanto a apocalíptica "fornece o instrumentário simbólico à reflexão teológica". Dessa forma, o conflito entre o cristianismo e o Império Romano passa a ser encarado como uma guerra espiritual.

${ }^{70}$ CHOURAQUI, 1996, p. 94.

${ }^{71}$ ASLAN, 2013, p. 13-98.

${ }^{72}$ Aslan traz informações atualizadas e significativas a respeito da Palestina e das condições do povo judaico, mas quanto à afirmação de que Jesus pertencia ao grupo dos zelotas, tendo como base a apresentação de Jesus como alguém com "zelo" particular pelo Templo no Evangelho de João, é questionável. Ele utiliza o termo "revolucionário", tanto como substantivo para acenar pessoas ou grupos engajados em revoltas, quanto como adjetivo se referindo às mesmas pessoas ou grupos, sem nunca fazer sequer uma discussão conceitual básica (ASLAN, 2013, p. 99-100).

${ }^{73}$ CROSSAN, 1994, p. 352.

${ }^{74}$ HOORNAERT, Eduardo. Em busca de Jesus de Nazaré: uma análise literária. São Paulo: Paulus, 2016. p. 33.

75 SCHIAVO, 2006, p. 100. 
Todavia, os atos de exorcismos não foram exclusivos de Jesus. Os discípulos deram seguimento a essa prática de Jesus. Rabuske ${ }^{76}$ destaca as referências da atividade exorcista da parte dos discípulos de Jesus em Marcos:

- $\quad$ Marcos 3.15; 6.7; 6.13, paralelo em Mateus 10.1; 10.8: os discípulos são enviados por Jesus com a tarefa de expulsar demônios, dentre outras;

- Marcos 16.17: retoma-se o exorcismo como sinal dos que creem em Jesus;

- Marcos 9.38-41, paralelo em Lucas 9.49s: alguém expulsa demônios em nome de Jesus.

$\mathrm{O}$ autor dá sentido às narrativas históricas de Jesus, no plano das representações, com vistas à destruição do imaginário coletivo negativo imposto pelo Império Romano, ainda presente na comunidade marcana. ${ }^{77}$ Comunidade que tinha como missão dar continuidade às atividades de Jesus.

\section{Considerações finais}

As legiões romanas e a morte de cruz marcavam fortemente o imaginário dos habitantes da Palestina no primeiro século. O projeto de libertação de Jesus se contrapõe ao projeto da Pax Romana sustentada pelo exército com suas violentas legiões romanas. Assim, ele é considerado subversivo e condenado à vergonhosa morte de cruz.

No entanto, logo após a guerra judaica de 66-70 d.C. e a consequente derrota dos judeus, bem como a humilhação na imposição opressora ampliada pelos romanos aos judeus e relacionados, como as comunidades cristãs que ainda eram confundidas com uma religião judaica, o autor do Evangelho de Marcos interpreta as práticas de exorcismos de Jesus e seus seguidores como movimento vitorioso de resistência popular não violenta à opressão romana. Uma forma efetiva de motivação da comunidade, que era a continuidade do movimento de Jesus, e ainda sofria com a opressão do Império Romano, sustentado por meio de suas legiões e a imposição da vergonhosa morte de cruz aos subversivos.

Assim sendo, os atos de exorcismos de Jesus, numa leitura anti-imperialista, podem ser interpretados como um movimento de resistência popular não violenta à opressão romana e meio de descontruir o imaginário popular palestinense negativo do primeiro século.

\section{Referências}

ASLAN, Reza. Zelota: a vida e a época de Jesus de Nazaré. Rio de Janeiro: Zahar, 2013.

BARBAGLIO, Giuseppe. Jesus, hebreu da Galileia: pesquisa histórica. São Paulo: Paulinas, 2011.

${ }^{76}$ RABUSKE, 2001, p. 39.

${ }_{77}$ Optou-se por destacar a perícope de Mc 5.1-17 por abordar especificamente a expulsão de uma legião, um dos temas principais desta pesquisa. No entanto, o Evangelho de Marcos possui outras perícopes como Mc 1.21-28; Mc 7.24-30, que possivelmente fazem parte do mesmo esquema literário. 
BARTH, Gerhard. Ele morreu por nós: a compreensão da morte de Jesus Cristo no Novo Testamento. São Leopoldo: Sinodal, 1997.

BERGER, Klaus. Hermenêutica do Novo Testamento. São Leopoldo: IEPG; Sinodal, 1999. BIETENHARD, H. "Ekballlo”. In: COENEN, Lothar; BROWN, Colin (Orgs.). Dicionário Internacional de Teologia do Novo Testamento. 2. ed. Trad. Gordon Chown. São Paulo: Vida Nova, 2000. v. 1, p. 517-518.

BORTOLINI, J. O evangelho de Marcos. São Paulo: Paulus, 2003.

BROWN, Raymond Edward. Introdução ao Novo Testamento. São Paulo: Paulinas, 2004.

BRUNT, P. A. Laus imperii. In: HORSLEY, R. A (Org.). Paulo e o Império: religião e poder na sociedade imperial romana. São Paulo: Paulus, 2004a.

CHAMPLIN, R. N. Enciclopédia de Bíblia, Teologia e Filosofia. 6. ed. São Paulo: Hagnos, 2002. CHOURAQUI, A. Marcos. Rio de Janeiro: Imago, 1996.

CROATTO, José Severino. Isaías: la palabra profética y su relectura hermenêutica. Buenos Aires: LUMEN, 1994. v. 2.

CROSSAN, John Dominic. Jesus: uma biografia revolucionária. Rio de Janeiro: Imago, 1995. O essencial de Jesus: frases originais e primeiras imagens. Belo Horizonte: Jardim dos Livros, 2008.

OJesus histórico: a vida de um camponês judeu do Mediterrâneo. Trad. André Cardoso.

Rio de Janeiro: Imago, 1994.

ELLIOTT, Neil. A mensagem anti-imperial da cruz. In: HORSLEY, R. A. (Org.). Paulo e o Império: religião e poder na sociedade imperial romana. São Paulo: Paulus, 2004b. p. 169-184. . A arrogância das nações: A Carta aos Romanos à sombra do Império. São Paulo: Paulus, 2010.

FABRIS, Rinaldo. Jesus de Nazaré: História e interpretação. São Paulo: Loyola, 1988.

FRANCO, H. Jr. Cocanha - a história de um país imaginário. São Paulo: Companhia das Letras, 1998.

GRABBE, Lester L. The Hellenistic City of Jerusalem. In: BARTLETT, John R. (Ed.). Jews in the Hellenistic and Roman Cities. London: Routledge, 2002. p. 6-21.

GRENZER, Matthias; FERNANDES, Leonardo Agostini. Evangelho Segundo Marcos: eleição, partilha e amor. São Paulo: Paulinas, 2012.

HENGEL, M. Crucifixion: in the ancient world and the folly of the message of the cross. Fortress: Philadelphia, 1978.

HOORNAERT, Eduardo. Em busca de Jesus de Nazaré: uma análise literária. São Paulo: Paulus, 2016.

HORSLEY, Richard A. Jesus e o império: o Reino de Deus e a nova desordem mundial. Trad. Euclides L. Calloni. São Paulo: Paulus, 2004a.

. Paulo e o império: religião e poder na sociedade imperial. São Paulo: Paulus, 2004b. . Hearing the whole story: the politics of plot in Mark's Gospel. Louisville: Westminster

John Knox, 2001. . Jesus e a Espiral da Violência. São Paulo: Paulus, 2010.

HORSLEY, Richard A.; HANSON, John S. Bandidos, Profetas e Messias: Movimentos Populares no Tempo de Jesus. Trad. Edwino A. Royer. São Paulo: Paulus, 1995.

KOESTER, Helmut. Introdução ao Novo Testamento. São Paulo: Paulus, 2005. v. 1.

MALINA, Bruce J. O Evangelho Social de Jesus: o Reino de Deus em Perspectiva Mediterrânea. Trad. Luiz Alexandre Solano Rossi. São Paulo: Paulus, 2004.

MEIER, John Paul. Um judeu marginal: repensando o Jesus histórico. Trad. Laura Rumchinsky. Rio de Janeiro: Imago, 1998. v. II, Livro 3.

MYERS, Ched. O Evangelho de Marcos. Trad. I. F. L. Ferreira. São Paulo: Paulinas, 1992. 
PAGOLA, Jose A. Jesus, aproximação histórica. Petrópolis: Vozes, 2010.

RABUSKE, Irineu J. Jesus exorcista: estudo exegético e hermenêutico de Mc 3,20-30. São Paulo: Paulinas, 2001.

RICHTER REIMER, Ivoni. Milagre das mãos: curas e exorcismos de Jesus em seu contexto histórico-cultural. São Leopoldo: Oikos; Goiânia: UCG, 2008.

ROSSI, Luiz Alexandre S. Messianismo e modernidade: Repensando o messianismo a partir das vítimas. São Paulo: Paulus, 2008.

. "Meu nome é Legião" - Uma leitura de Marcos 5,1-17 a partir da ação letal da legião romana. Revista Reflexus, v. 5, n. 6, p. 177-188, 2011.

RÜSEN, Jörn. História Viva. Teoria da história: formas e funções do conhecimento histórico. Brasília: UnB, 2007.

SCHIAVO, Luigi. 2000 Demônios na Decápole: exegese, história, conflitos e interpretações de Mc 5,1-20. 1999. Dissertação (Mestrado em Ciências da Religião) - Universidade Metodista de São Paulo, São Bernardo do Campo, 1999. 236 p.

SCHIAVO, Luigi. Anjos e Messias: messianismos judaicos e origem da cristologia. São Paulo: Paulinas, 2006.

SILVA, Cássio Murilo Dias da. Metodologia de exegese bíblica. 2. ed. São Paulo: Paulinas, 2003. SOARES, Sebastião Armando Gamaleira; CORREIA JÚNIOR, João Luiz. Evangelho de Marcos: Vol 1:1-8, Refazer a casa. Petrópolis: Vozes, 2002.

SOUTHERN, P. The Roman Army. Oxford: Oxford University Press, 2007.

STEGEMANN, Ekkehard W.; STEGEMANN, Wolfgang. História social do protocristianismo: os primórdios no judaísmo e as comunidades de Cristo no mundo mediterrâneo. São Paulo: Paulus; São Leopoldo: Sinodal, 2004.

STORNIOLO, Ivo. Como ler o Evangelho de Mateus: o caminho da justiça. São Paulo: Paulus, 1991.

. Como ler o evangelho de Lucas. São Paulo: Paulus, 1992.

WENGST, C. Pax Romana: pretensão e realidade. Tradução de Antônio M. da Torre. São Paulo: Paulinas, 1991. 